\title{
Legal Issues in Mental Health Education in Universities
}

\author{
Dongmei Zhao
}

Qilu University of Technology, Jinan 250353, Shangdong, China.

Abstract: College students as an important backbone to achieve national rejuvenation, so to ensure students' mental health, and to establish the correct values and ideological and moral levels, becomes a problem that teachers in colleges and universities need to focus on solving. Effectively solving high-quality legal problems in mental health education can not only ensure the smooth progress of teaching work, but also accurately handle students' psychological problems and enable them to develop better. This article starts from multiple angles and seeks to solve the legal problems arising in the process of mental health teaching, hoping to provide reference for education peers.

Keywords: Legal Issues; Higher Education; Psychological Quality; Mental Health Education

Although college students have passed the puberty period, they are still in a stage of very active thinking and consciousness. Therefore, students in this period are easily confused and confused under the influence of psychological conflicts, and they need to establish correct behavioral awareness under the correct guidance of psychological teachers.

\section{Strictly implement teacher professional qualification management}

As a profession that can influence people's values and behavior consciousness, psychological counseling has high requirements for practitioners' moral quality, professional functions and professional literacy. Only after specialized study and practice can we obtain professional qualification certification through rigorous examinations. Many Western countries usually incorporate the process of psychological counselor training into legal guidelines. It requires learners to enter a specialized university to complete relevant courses, to carry out skills training, qualification review, practical training activities, obtain qualification certificates, and participate in employment, etc., and All contents are indispensable to become a qualified counselor. Many colleges and universities do not have high requirements when recruiting mental health teachers, and they do not have mandatory requirements for teachers' professional qualification certificates. This leads to the situation that teachers have weak teaching skills and it is difficult to ensure the orderly development of mental health education. This requires teachers to be able to pay attention to the importance of strictly implementing the professional qualification management of psychology teachers. Practicing teachers must obtain relevant qualification certificates, participate in practical training activities on a regular basis, and respond to teacher assessment rewards, learning requirements, job development and other content. Improve and fully mobilize the enthusiasm of teachers to make full use of their teaching abilities and professional qualities, to avoid the problems of breaking the law in the development of education, and to ensure the high-quality development of mental health education.

\section{Pay attention to the importance of privacy protection}

To achieve better results in mental health education, students need to be able to tell their teachers what they think from the

Copyright $(2020$ Dongmei Zhao

doi: 10.18686/ahe.v4i10.2950

This is an open-access article distributed under the terms of the Creative Commons Attribution Non-Commercial License (http://creativecommons. org/licenses/by-nc/4.0/), which permits unrestricted non-commercial use, distribution, and reproduction in any medium, provided the original work is properly cited. 
heart, so that they can find specific directions to help students solve problems, so many psychological work is inevitable and consultation The privacy of the person. Privacy refers to the secrets that people only enjoy, which are neither related to public interests nor shared with others, so they generally show the characteristics of privacy. As an important part of civil law, the protection of personal privacy is protected by the state. Since the development of higher mental health education in China is a bit later than in Western countries, many psychology teachers are teachers specializing in pedagogy, ideology, politics, and psychology. At the same time, there are obvious differences in professional levels, and professional qualities are also uneven, so often lack of awareness of maintaining the privacy of psychological counselors. Therefore, mental health teachers need to clarify their position in education. They are not only teachers who teach students' knowledge, but also managers who regulate students' behavioral awareness. Only through the importance of Chinese privacy protection can they seek to observe the principle of confidentiality without violating public order and good customs. And legal norms. At the same time, teachers also need to pay attention to the proper management of information files to avoid leaking the privacy of consultants due to poor file management, in order to maximize the protection of students' privacy and help them successfully solve the problems they face.

\section{Actively promote the standardization of psychometric work}

Many colleges and universities require students to fill out the psychological measurement evaluation form in the psychological column of the campus network when they first enter the school, so that psychological teachers can find problems according to the psychological conditions of students and make more targeted mental health education programs. But the reality is that the use of psychological measurement evaluation forms has greater inaccuracies, such as whether students fill out truthfully, whether the testers are professional, whether the evaluation results are reasonable, and whether the measurement table selection meets the actual requirements of students. At present, policies and regulations do not regulate the use of psychometric evaluation forms, but colleges and universities still need to actively promote the standardization of psychometric work to enable it to be carried out on the basis of compliance with legal regulations. For example, schools need to inspect the assessment teachers' psychological and professional qualifications to ensure that their professional level, assessment ability and professional level can meet the teaching requirements. At the same time, the school also needs to select the measurement evaluation form based on the comprehensive consideration of the test environment, evaluation purpose, testing personnel and measurement nature according to the overall situation and psychological needs of the students, so that the measurement work can be carried out in the process of standardization to ensure mental health education. Implement in an orderly manner as permitted by law.

\section{Conclusion}

As the university students shoulder the responsibility of promoting the country's future vigorous development, their own mental health is particularly important. Therefore, many colleges and universities attach great importance to the development of mental health teaching activities, hoping that students can grow into high-quality talents with tenacity, perfect personality and correct values under the correct guidance of teachers. In order to ensure the orderly progress of educational work, teachers need to ensure the high-quality development of mental health teaching activities, on the other hand, they need to study and solve the legal problems that exist in them. This can not only achieve the purpose of improving the effectiveness of education, but also promote the rapid development of my country's higher education in the process of better guiding students' mental health development.

\section{References}

1. Liu Y, Shen BX, Wang MD, et al. The reform and exploration of the university mental health general education model based on the concept of curriculum ideology and politics. University Education 2020; (07): 79-81.

2. Li HM, Song SY, Dong CY, et al. Research on mental health education in colleges and universities from the perspective of “sanquan educating people". Journal of North University of China (Social Science Edition) 2020; 36(04): 41-45.

3. Huang B. Research on mental health education of college students majoring in physical education from the perspective of ideological and political education_C Comment on "mental health education and ideological and political education in universities”. Leadership Science 2020; (10): 128. 